\title{
Missile materials-Current status and challenges
}

\author{
V J SUNDARAM \\ Defence Research and Development Laboratory, Research Centre Imarat, Hyderabad \\ 500058 , India
}

\begin{abstract}
Missile Development Programme has provided focal thrust to indigenous materials and components. Materials have been selected on the basis of their high strength to weight ratio, good corrosion resistance, high fracture toughness, easy fabricability and reliable quality. Alloys of magnesium, aluminium, titanium and maraging steel are extensively used for airframe and propulsion systems. Polymer materials and carbon-carbon composites are major nonmetallic materials. Development of high purity electronic materials like silicon, indium, phosphorus, Cu clad materials, photo resists and epoxies are very important for the programme. The paper covirs the requirements and challenge areas of research, and calls for consortium approach involving academic institutions. $\mathrm{R}$ and $\mathrm{D}$ laboratories and industries to ensure self reliance.
\end{abstract}

Keywords. Missile materials; current status; challenges.

\section{Introduction}

Integrated Guided Missile Development Programme (IGMDP) has a focal thrust on indigenous components and materials. The design is based on available technology, and the expertise required has been tapped from wherever available within the country. Materials form the basis of the programme. A wide variety of materials have been selected, qualified and used as finished products. This paper covers the major aspects of materials currently used, and outlines some of the challenge areas.

\section{Design and quality requirements}

Materials being used for missile programme have some of the specific design and quality requirements as listed below:

* high strength to weight ratio (to have the structure as light as possible)

* good corrosion resistance (to avoid improper performance during storage)

* high fracture toughness

* good fabricability (castability, weldability, formability)

* defect detectability

* reliable quality

\section{Metallic materials}

\subsection{Magnesium alloys}

Magnesium alloys are used for outer shells, wings and control surfaces due to their low density (resulting in lower weight) and good damping capacity. 
The challenge areas for realizing large size magnesium alloy casting and plates are:

* development of technology for casting, forging, rolling and heat treatment.

* establishing CNC machining technique for fabrication of precision profiled components

* development of anticorrosion treatments and vacuum impregnation techniques for ensuring storage life.

Agencies like HAL, DMRL, MIDHANI and other private industries participated in this programme along with DRDL and made these components totally indigenous.

\subsection{Aluminium alloys}

Aluminium alloys are extensively used in the airframe structure and propulsion system in the form of sheets, ring rolled forgings, extrusions, forgings and castings. $\mathrm{Al}-\mathrm{Mn}-\mathrm{Si}-$ $\mathrm{Mg}$ alloys $(65032 \mathrm{~A})$ are selected for their good corrosion resistance, compatibility with fuel and oxidiser, good weldability, forgeability and heat treatability. The critical technologies that have been developed and set into production in the Indian industries are:

- production and qualification of aerospace quality alloy at BALCO

- chemical milling to reduce thickness of plate

- precision automatic TIG welding in a dustfree and humidity controlled clean room

- water quenching after solutionizing with a quench delay of less than 10 seconds

Four major industries in private and public sectors have developed and set up the production for the manufacture of propulsion tankages. This resulted in self reliance at multiple technology work centres.

The challenge areas for further study are:

- improving weldability of high strength IS: 24345 alloys

- improving the joining process through modelling and simulation studies

- improving the filler material chemistry to produce crack free high strength joints

- reduction of residual stresses causing dimensional distortions during heat treatment and machining

\subsection{Titanium alloys}

Titanium alloys ( $\mathrm{T} i-6 \mathrm{Al}-4 \mathrm{~V})$ are used for high pressure airbottles, sustainer casings and are basically selected due to their high strength at half the density of steel. They are also selected for their excellent corrosion resistance. Titanium alloy hemispheres are formed by hot forging, pressing and superplastic forming routes and are joined by TIG and electron beam welding methods.

The critical $R$ and $D$ areas are:

- development of filler for high strength and toughness

- technology for rolling of their sheets

- diffusion bonding of titanium alloys 


\subsection{High strength steels}

Maraging steel (MDN-250) is used for rocket motor casings and combustion chambers. This high strength steel is selected due to its high fracture toughness combined with high strength and less distortion due to absence of water quenching after heat treatment.

Critical technologies like flow forming, controlled heat treatment, forging and welding have been well established and set into production at various industries.

Current interest is to replace this costly steel with many ingredients currently imported by an alternative $\mathrm{Ni}-\mathrm{Si}-\mathrm{Cr}-\mathrm{Co}$ steel developed at DMRL, and also for the development of corrosion resistant steels for marine atmosphere.

The critical $\mathrm{R}$ and $\mathrm{D}$ efforts are required to develop (i) coating processes for fasteners with less danger of hydrogen embrittlement, (ii) air hardening techniques for distortionless quenching of high-strength steels and (iii) corrosion resistance steels for marine atmosphere.

\subsection{Other metallic materials}

Soft magnetic alloys, controlled expansion alloys, hard tungsten alloy spheres, nickel based super alloys, berillium copper and oxygen free high conductivity copper are extensively used in gyroscope, accelerometer and other control and guidance system components.

The critical $R$ and $D$ areas are:

- manufacture and qualification of the alloys in small quantities

- characterization of magnetic, electrical and thermal expansion properties of indigenous alloys

- fabrication of molybdenum boats required for sintering of warhead spheres made through powder metallurgical route

\section{Electronic materials}

Electronic materials throw open a number of challenges to Indian scientific community. While component level production is on in many agencies like BEL, ITI, ECIL, SCI etc the basic raw materials are getting imported in many cases. The current $R$ and $D$ requirements should be assessed by scientists, laboratories and industries in this area.

\section{Non metallic materials}

\subsection{C-C composites}

Carbon-carbon composites have advantages over other aerospace materials in the following areas:

* thermally stable and do not melt up to $3000^{\circ} \mathrm{C}$

* possess high thermal conductivity and low thermal expansion (resulting in high resistance to thermal shock)

* retention of mechanical strength and maintenance of good frictional properties over different temperature ranges 
The stages involved in manufacturing $\mathrm{C}-\mathrm{C}$ products are:

* 3-D weaving of preform with carbon yarn

* pitch impregnation at $300-400^{\circ} \mathrm{C}$

* Carbonization at $1000^{\circ} \mathrm{C}$

* Hot isostatic pressing at $850^{\circ} \mathrm{C}$ and $1000 \mathrm{~kg} / \mathrm{cm} \mathrm{sq}$

* Graphitization at $2750^{\circ} \mathrm{C}$

The thrust $\mathrm{R}$ and $\mathrm{D}$ areas in $\mathrm{C}-\mathrm{C}$ composites are:

* heat transfer analysis in a solid domain with time dependant heat flux

* thermostructural analysis using simulated conditions

* qualification testing (flexural load vibration and ground resonance testing)

* microstructural analysis to evaluate the distribution of fibres and matrix, pore distribution, isotropy and unisotropy of matrix formation and damage analysis

* evaluation of pitch impregnation parameters and optimization of densification efficiency

\subsection{Polymeric materials}

Polymeric materials have applications in missiles in the following areas:

- propulsion system as high energy polymer binders for composite propellants, with high hydrogen to carbon ratio, low exhaust molecular weight, higher combustion temperature and burning rates and specific impulse

- as lining materials for combustion chambers with high thermal stability, 'char' value, and low thermal conductivity. They also have high toughness values, but not too high to develop cracks, and high adhesive properties with steel/Al castings and reinforced fibres like carbon, glass and asbestos

- as thermally stable ablative polymer for protection of chambers from thermal erosions. Ablators are of thermosetting, thermoplastic, silicone phenolic resin or FRP based

- as polymeric coatings/paints for missile launchers to provide protection in marine atmosphere against abrasion, corrosion and erosion

- as adhesives for metal to metal bondings and carbon-FRP bonding and as elastomeric sealants for metal bonding

- as antimixing additives to reduce risk of fire and as elastomers for rubber hoses, flexible pipes, diaphragms, sealants etc

- as plastic components to provide optical and radar transparencies in electrical and electronic components

The challenge $R$ and $D$ areas are:

- on predicting life of polymers after they have been used

- on third generation molecular composites [homogenous synergistic composites of molecularly dispersed and intrinsically rigid and flexible coil macro molecules]

\section{Conclusions}

(I) Missile materials are selected based on their special characteristics like highstrength to weight ratio, fracture toughness, good corrosion resistance, easy fabricability and reliable quality. 
(II) Metallic materials like alloys of magnesium, aluminium and titanium and maraging steel are extensively used along with nonmetallic materials like polymers and carbon-carbon composites.

(III) Electronic material development and production within the country is an immediate requirement.

(IV) The major thrust areas are in characterization of new materials, production at laboratory and pilot plant scale through consortium approach and standardization of cost effective and reliable production technology. Academic, $R$ and D laboratory and industry linkages should be established to face the challenges in manufacture of Indian materials for missile programme. 